\title{
Analysis the Effectiveness of Three Online Vocabulary Flashcard Websites on L2 Learners' Level of Lexical Knowledge
}

\author{
Chin-Wen Chien ${ }^{1}$ \\ ${ }^{1}$ Department of English Instruction, National Hsinchu University of Education, Taiwan \\ Correspondence: Chin-Wen Chien, Department of English Instruction, National Hsinchu University of \\ Education, Hsinchu 300, Taiwan. Tel: 886-3-5213132 ext.6712. E-mail: chinwenc@ms24.hinet.net
}

Received: February 10, 2015 Accepted: March 12, 2015 Online Published: April 23, 2015

doi:10.5539/elt.v8n5p111 URL: http://dx.doi.org/10.5539/elt.v8n5p111

\begin{abstract}
This study compared and contrasted 64 Taiwanese college freshmen's perceptions of and attitudes toward three online vocabulary flashcard websites, Quizlet, Study Stack, and Flashcard Exchange. Four types of data were collected in two freshmen English classes in a university in Taiwan from February to April 2013. Data included online flashcard websites, classroom observations, participants' online flashcards and learning records, and interview. The study has the following two findings. First, these three online vocabulary flashcard websites mainly offered freshmen with the word knowledge in terms of form and words' meaning. Second, participants held positive attitudes toward learning and improving their vocabulary abilities via online flashcards and their related activities. Suggestions are provided to make online flashcards more effective vocabulary-learning tools: provision of user-friendly guidelines on using online flashcards, provision of flashcards with word meanings and related information, and a variety of easy exercises designed to develop learners' word knowledge.
\end{abstract}

Key words: form, vocabulary flashcard, vocabulary learning, word knowledge, word meaning

\section{Introduction}

Vocabulary is essential for communication. Language learners may feel discouraged if they lack sufficient vocabulary knowledge and strategies for learning new words (Nation, 2001). In order to expand vocabulary knowledge, language learners can be taught to be familiarized with useful supplementary materials, such as word lists or vocabulary flashcards (Baleghizadeh \& Ashoori, 2011; Nation, 2001). Vocabulary learning can be categorized into incidental and intentional learning. Intentional learning refers to "any activity aiming at committing lexical information to memory" (Robinson, 2001, p. 271). Vocabulary learning with computers can be more effective than through the use of traditional learning methods such as dictionaries. Vocabulary learning via technology enables learners to be exposed to repetition of vocabulary, which is believed to be more effective than massed repetition (Nation, 2001).

Flashcards are sets of cards that bear information. Language teachers often use flashcards when introducing new vocabulary words. Flashcards usually have words on one side and pictures or definitions on the other side. Integration of multimedia into English learning and teaching has become a trend (Hu \& Deng, 2007; Hubbard, 2012). Multimedia has been integrated into vocabulary learning, such as pre-packaged computer programs, word annotations, glossing, online dictionaries, or online flashcards. Online flashcards can be easily accessed by language learners to review vocabulary words.

The current empirical studies on online flashcards explore the components, designs, and games of flashcards without using vocabulary learning framework (Baturay, Yıldırım, \& Daloğlu, 2009; Tuite, Pavlik, Fan, Robison, Jaffe, \& Liu, 2012). Nakata's (2011) “Criteria for Evaluating Flashcard Software" and Nation's (1994) "Activities for Vocabulary Learning" are used to compare and contrast three online vocabulary flashcard websites and their exercises in terms of the word knowledge acquired. This study also compares and contrasts college freshmen's perceptions of and attitudes toward three online vocabulary flashcard websites and exercises. Suggestions for the flashcard websites are provided in terms of flashcard and activity designs.

\section{Literature Review}

Research demonstrates that building vocabulary knowledge requires more than accumulating facts about specific elements such as word definitions (Baumann \& Kammeenui, 1991; Benjamin \& Crow, 2010; Nagy \& Scott, 
2000; Stahl, 2005). Language learners' word knowledge should include a word's derivation, gender, grammatical environment, idioms, intentions, meaning, opposite, pronunciation, spelling, connotation, register, and collocation (Benjamin \& Crow, 2010). In order to help learners acquire word knowledge in terms of its form, use, and meaning, Nation (1994) suggests a number of activities, as set out in Table 1. Take the spoken form as an example: Activities on websites can be designed for learners to learn how to pronounce a word, read aloud, or record it.

Table 1. Activities for vocabulary learning (Nation, 1994)

\begin{tabular}{|c|c|c|}
\hline Goal & Elements & Activities \\
\hline \multirow[t]{18}{*}{ Form } & \multirow[t]{2}{*}{ spoken form } & . Pronounce the words \\
\hline & & . Read aloud \\
\hline & \multirow[t]{2}{*}{ written form } & . Word and sentence dictation \\
\hline & & . Finding spelling rules \\
\hline & \multirow[t]{4}{*}{ word parts } & . Filling word part tables \\
\hline & & . Cutting up complex words \\
\hline & & . Building complex words \\
\hline & & . Choosing a correct form \\
\hline & \multirow[t]{5}{*}{ form-meaning connection } & . Matching word and definitions \\
\hline & & . Discussing the meanings of phrases \\
\hline & & . Drawing and labeling pictures \\
\hline & & . Peer teaching \\
\hline & & . riddles \\
\hline & \multirow[t]{5}{*}{ concept and reference } & . Finding common meanings \\
\hline & & . Choosing the right meanings \\
\hline & & . Semantic feature analysis \\
\hline & & . Answering questions \\
\hline & & . Word detective \\
\hline \multirow[t]{10}{*}{ Meaning } & \multirow[t]{8}{*}{ Association } & . Finding substitutes \\
\hline & & . Explaining connections \\
\hline & & . Making word maps \\
\hline & & . Classifying words \\
\hline & & . finding opposites \\
\hline & & . Suggesting causes or effects \\
\hline & & . Suggesting associations \\
\hline & & . Finding examples \\
\hline & \multirow[t]{2}{*}{ Grammar } & . Matching sentence halves \\
\hline & & . Putting words in order to make sentences \\
\hline \multirow[t]{4}{*}{ Use } & \multirow[t]{2}{*}{ Collocations } & . matching collocates \\
\hline & & . finding collocates \\
\hline & \multirow[t]{2}{*}{ Constraints on use } & . identifying constraints \\
\hline & & classifying constraints \\
\hline
\end{tabular}

Learners nowadays favor the integration of multimedia and technology into their learning, rather than traditional types of instruction. The integration of multimedia into vocabulary learning has had a number of recorded effects 
on English as a foreign language (EFL) learners in accordance with the different natures of the programs, such as pre-packaged computer programs, web-based programs, online flashcard games, online workbooks, online dictionaries, word annotations, or glossing (Ali, Mukundan, Baki, \& Ayub, 2012; Baturay et al., 2009; Tuite et al., 2012).

Flashcards are excellent English teaching tools when teachers are introducing new vocabulary words and drill practice. Nakata (2011) uses 17 criteria to analyze and evaluate nine flashcard programs in terms of two categories: flashcard creation and editing as well as learning. With regard to flashcard creation and editing, the following six criteria are used: 1) flashcard creation, 2) multilingual support, 3) multi-word units, 4) types of information, 5) support for data entry, and 6) flashcard set (p. 28). As for learning, the following 11 criteria are used: 1) presentation mode, 2) retrieval mode, 3) receptive recall, 4) receptive recognition, 5) productive recall, 6) productive recognition, 7) increasing retrieval effort, 8) generative use, 9) block size, 10) adaptive sequencing, and 11) expanded rehearsal (p. 29).

Flashcards are excellent English teaching tools when teachers are introducing new vocabulary words and drill practice. Tuite et al. (2012) conclude that Picard, a Facebook game for studying flashcards, is a fun and effective environment for learners to memorize words in different fields, because Picard provides input by players with their own mnemonic devices and a social environment for players to communicate and help each other learn and stay motivated. The Word Engine, designed by Browne and Culligan (2008), provides flashcards with definitions in English, learners' first language, parts of speech, sound files with native speakers' pronunciation of the words, frequent collocations, and sample sentences. Two games were provided for learners to review: 1) Sight Words (Students are asked to quickly match the word to the correct response) and 2) Sound-Bubbles (Students first click on a bubble to hear a word pronounced and then match a correct response to each sound bubble). Moreover, $\mathrm{V}$-Admin was used to generate individualized quizzes based on the words the students are studying for in-class testing, thus providing an external check to the activity reports. Browne and Culligan (2008) claim Word Engine provides a new type of self-access center for learners in vocabulary learning.

Online flashcards can be easily accessed by language learners for review of vocabulary words. Current studies conclude that EFL learners learn more vocabulary words via annotation containing text, sound, and pictures or games with words in the target language and L1 equivalent counterparts. Few studies have focused on the integration of online flashcards with EFL learners' vocabulary learning: so far, only four studies (Baturay et al., 2009, Browne \& Culligan, 2008; Daloglu, Baturay, \& Yildirim, 2009; Tuite et al., 2012) have focused on the introduction of online vocabulary flashcards and accompanied games, and these studies focus on one specific online vocabulary flashcard tool in terms of its components, designs, and accompanied games. This study adopts Nakata's (2011) "Criteria for Evaluating Flashcard Software" and Nation's (1994) “Activities for Vocabulary Learning" to compare and contrast not only three online vocabulary flashcard websites and the exercises, but also college freshmen's perceptions of and attitudes towards these websites and activity designs.

\section{Method}

This case study aims to compare and contrast three online vocabulary flashcard websites and their characteristics, as well as to discover college freshmen's perceptions of these online vocabulary flashcard websites. Yin (2008) defines case study as "en empirical inquiry that investigates a contemporary phenomenon within its real-life context" (p. 18). A case has a bounded system, a single entity, a unit which there are boundaries (Merriam, 2009). The case here includes two classes of 64 freshmen. The unit of analysis is the college freshmen's perceptions and experience of these three websites.

This study answers the following two questions: 1) What word knowledge can the exercises and flashcards on the online vocabulary flashcard websites provide? 2) What are Taiwanese college freshmen's attitudes toward and perceptions of these vocabulary flashcards in terms of their vocabulary learning and word knowledge acquisition?

\subsection{Research Setting and Participants}

Convenience sampling was used in this study. The study was conducted over three months from February to April 2013. The class met for two hours per week in the 2013 spring semester. The participants included one instructor and two freshman English classes of 64 students in a university in Taiwan. The majority of the students were Education majors, followed by Chinese and Art and Design majors. Only one student was from Educational Psychology and Counseling.

As for their English learning experience, 42 of them had been learning English for 6-10 years. While 16 of participants had been learning English for more than 10 years, six had less than five years of English learning 
experience. About $69 \%$ of the participants had learned English outside of the compulsory English classes.

\subsection{Data Collection}

The major data in this study included 1) three online flashcard websites; 2) classroom observations; 3) online flashcards and records of practicing and reviewing words on Quizlet.com (hereafter Quizlet), Study Stack.com (hereafter Study Stack), and Flashcard Exchange.com (hereafter Flashcard Exchange); and 4) interview.

Quizlet, Study Stack, and Flashcard Exchange are three online websites. These three online websites were chosen because they can provide free vocabulary flashcards. The researcher has no financial interest with any of these online websites. Moreover, anyone can log into these websites through their Facebook accounts or create their own accounts. Unlike other ready-made flashcard websites or programs (i.e. Word Engine, Picard) that provide flashcards only on specific words, users can have autonomy by creating a set of vocabulary by typing in words and definitions on their own.

In the first class, the instructor explained the steps involved in making vocabulary flashcards in Quizlet, Study Stack, and Flashcard Exchange. Freshmen chose one unit covered in Reading Explorer 3, the required textbook, and made flashcards for words related to that topic. They practiced games and activities provided on Quizlet, Study Stack, and Flashcard Exchange. The instructor created a community on Quizlet, Study Stack, and Flashcard Exchange and all the participants could read the flashcards made by other students. Freshmen could review words either on the Quizlet, Study Stack, and Flashcard Exchange sites or through their mobile phones.

Observation is the most natural way to collect data. Classroom observations were conducted when freshmen made their flashcards in the language laboratory. The researcher took field notes of the instructor's explanations and demonstrations of using these three flashcard websites, these 64 participants' manipulation of three flashcard websites, and conversations between the instructor and participants as well as between participants and participants.

A total of 20 participants in this study were randomly chosen for the interview and divided into five groups. Each group interview lasted fifteen minutes. The semi-structure protocol was designed based on Nation's (1994) “Activities for Vocabulary Learning" and Aliet et al.'s survey (2012). Participants were asked three basic questions: 1) How did online flashcards and exercises help you learn vocabulary? 2) How did you feel about learning vocabulary through online flashcards and exercises? 3) Why are these online vocabulary websites easy to use? Why are they not easy to use? Participants answered either in English and Chinese.

\subsection{Data Analysis}

The data analysis was carried out in the following steps. First, the researcher used Nakata's (2011) "Criteria for Evaluating Flashcard Software" and Nation's (1994) "Activities for Vocabulary Learning” to analyze these three online flashcard websites and exercises. Second, after the interview and observation were transcribed, the researcher read through all the data and labeled the preliminary codes (i.e. word knowledge, receptive, productive). Third, guided by the research questions, issues were identified such as elements of online flashcards, designs of flashcard exercises, acquisition of word knowledge, or technological aspects.

\section{Results}

Results were focused on the activities offered by online vocabulary flashcards websites, observations of freshmen's experience of online flashcard websites, records of students' practice, and interview.

\subsection{Online Vocabulary Flashcard Websites}

Quizlet offers three learning activities: 1) Learn (read the definition and type in the word); 2) Speller (read the definition, listen to the sound clip, and type in the word); and 3) Test: a) Written Question (reading the definition and type in the word), b) Multiple-Choice Question (read the sentence and choose the best answer), c) True and False Question (read the word and check its definition). Quizlet also provides two games: 1) Scatter (match words with definitions), and 2) Space Race (speedy spelling) as in Figures 1 and 2. 


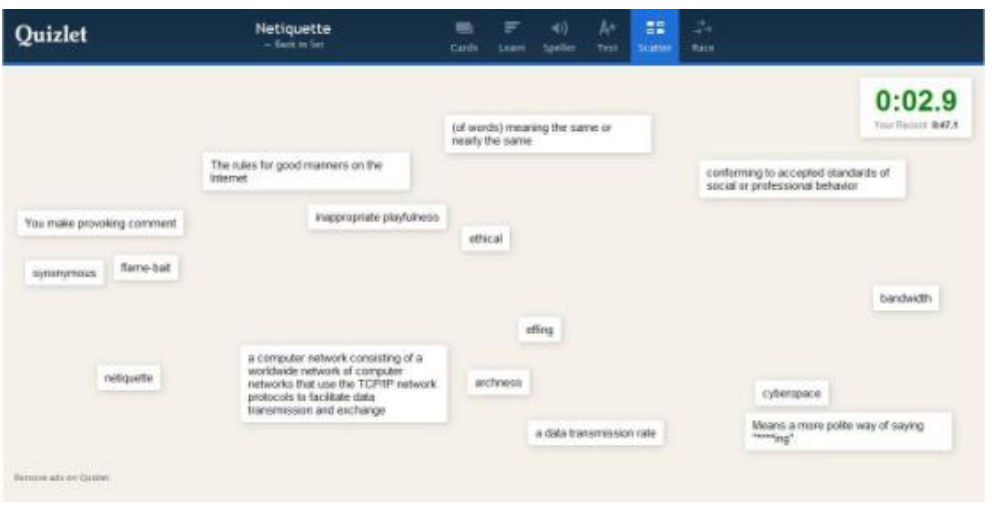

Figure 1. Scatter in quizlet

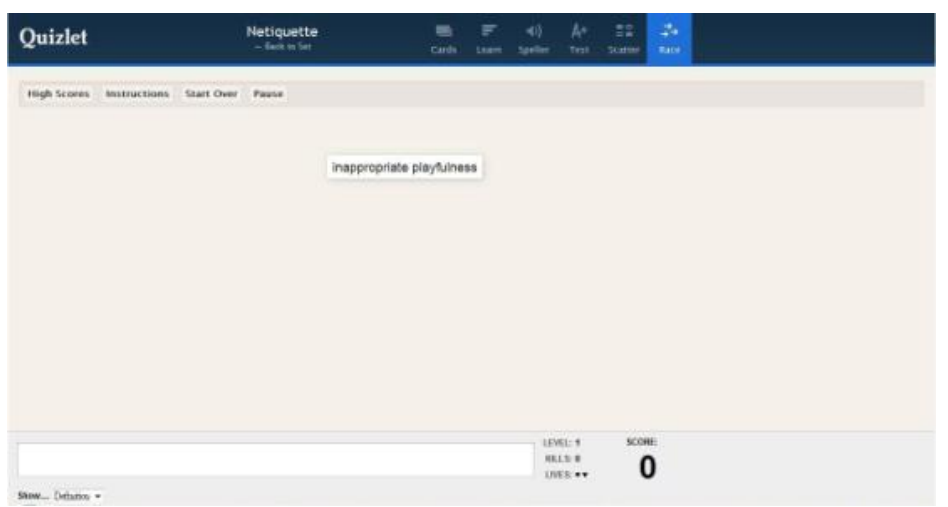

Figure 2. Space race in quizlet

Study Stack offers eight games: 1) Matching (Match words and their definitions); 2) Hangman (Use letters to spell the word); 3) Crossword (Read the definitions and type in the words); 4) Unscramble (put letters into the correct word); 5) Chopped (Read the definition and spell the words by putting parts of the words); 6) Fill in the blank (Read the definition and type in the word); 7) Quiz: a) read the definition and choose the correct answer from the four choices, b) read the word and choose the correct answer from the four definitions; and 8) Test: a) read the definition and choose the corresponding word, b) read the definition and type in the word. Figure 3 is an example of Chopped.

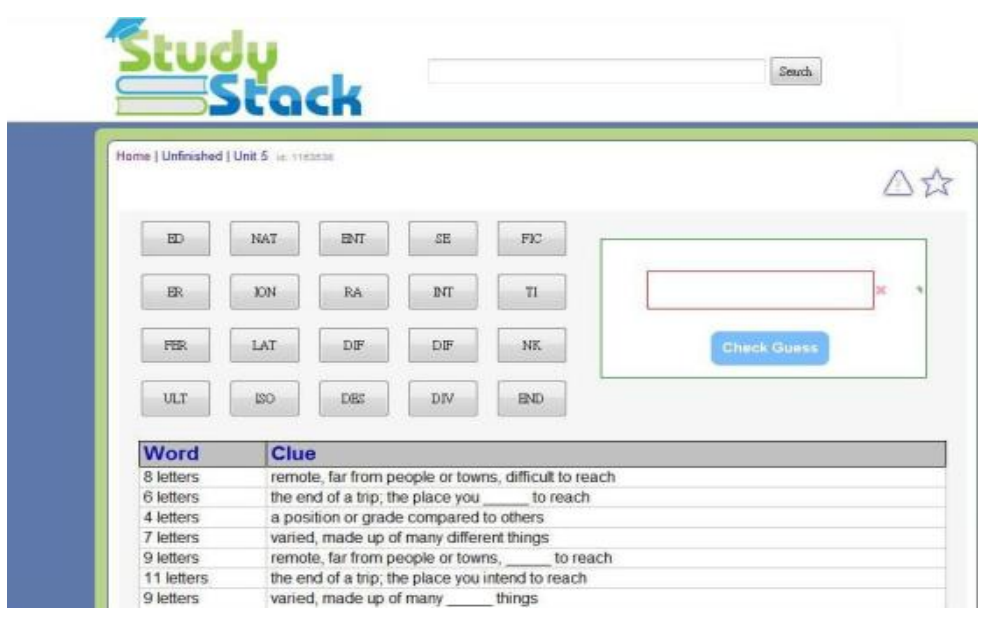

Figure 3. Chopped in study stack 
Flashcard Exchange provides two exercises: 1) Memorize (read the definition and click the See Answer button. Read the answer and decide if it is "Choose I Was Wrong" or "I Got it Right"); 2) Test (read the word and type in its definition). Figure 4 is an example of Memorize.

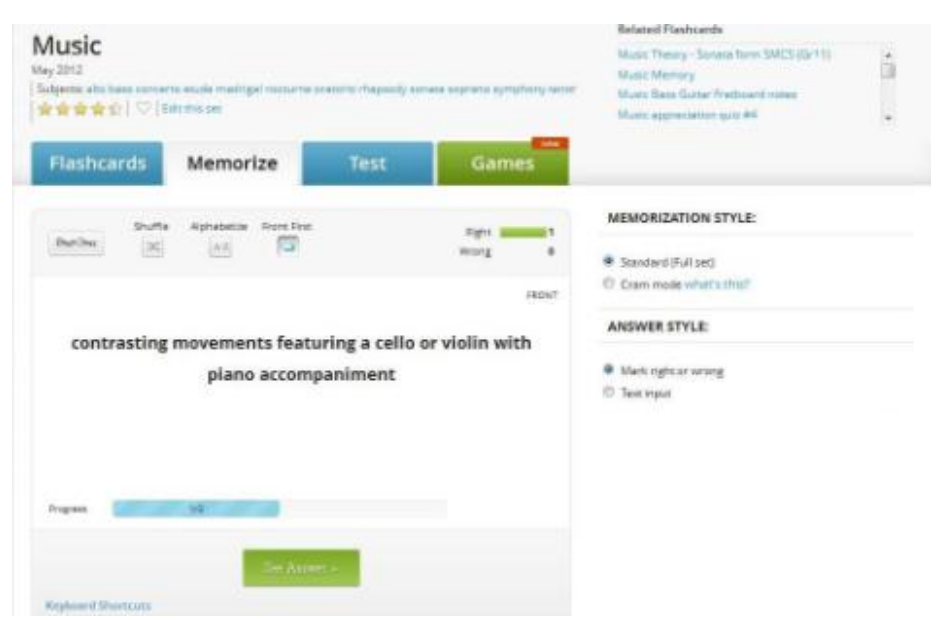

Figure 4. Memorize in flashcard exchange

As in Table 2, exercises offered in these three online vocabulary flashcard websites all focused on Nation's (1994) "form," particularly two elements "form-meaning connections" and "written forms." Learners match words and their definition when they play Matching in Study Stack. While activities on Quizlet and Study Stack included spelling, Quizlet also emphasized pronunciation. None of the exercises on these three websites focused on "meaning" (i.e. association, goal) and "use" (i.e. collocation, constraints of use). Teaching or learning words in isolation, or only word meanings, is insufficient in building learners' word knowledge.

Table 2. Comparisons and contrasts on online vocabulary flashcard websites based on Nation's (1994) activities for vocabulary learning

\begin{tabular}{lllll}
\hline Goal & Elements & Quizlet & Study Stack & Flashcard Exchange \\
\hline Form & spoken form & $\checkmark$ & & $\checkmark$ \\
& written form & $\checkmark$ & $\checkmark$ & $\checkmark$ \\
& word parts & & $\checkmark$ & \\
& form-meaning connection & $\checkmark$ & & \\
& concept and reference & & \\
\hline Meaning & Association & & \\
& Grammar & & \\
\hline Use & Collocations & & \\
& Constraints on use
\end{tabular}

Table 3 reveals the evaluation of online vocabulary flashcard websites and exercises based on Nakata's (2011) 17 criteria. With regard to flashcard creating and editing, all of these online vocabulary flashcard websites and exercises have flashcard creation, multilingual support, support for data entry, and flashcard set. Users can create their own flashcards by typing in one word and its corresponding definitions or translation or typing in one word and choosing the corresponding meanings provided by the websites. However, none of these websites provide multi-word units or different word knowledge (i.e. parts of speech, audios, contexts). 
Table 3. Comparisons and contrasts on online vocabulary flashcard websites based on Nakata's (2011) criteria

\begin{tabular}{lccc}
\hline Criteria & Quizlet & Study Stack & Flashcard Exchange \\
\hline I. Flashcard creating and editing & & & \\
1. flashcard creation & $\checkmark$ & $\checkmark$ & $\checkmark$ \\
2. multilingual support & $\checkmark$ & $\checkmark$ & \\
3. multi-word & & & \\
4. types of information & & & $\checkmark$ \\
5. support for data entry & $\checkmark$ & $\checkmark$ & $\checkmark$ \\
6. flashcard set & $\checkmark$ & $\checkmark$ & $\checkmark$ \\
\hline II. Learning & & & $\checkmark$ \\
1. presentation mode & $\checkmark$ & $\checkmark$ & \\
2. retrieval mode & $\checkmark$ & $\checkmark$ \\
3. receptive recall & & & $\checkmark$ \\
4. receptive recognition & & & \\
5. productive recall & & $\checkmark$ & \\
6. productive recognition & $\checkmark$ & $\checkmark$ & \\
7. increasing retrieval effort & & & \\
8. generative use & & & \\
9. block size & & & \\
10. adaptive sequencing & & & \\
11. expanded rehearsal & & & \\
\hline
\end{tabular}

In terms of learning, all these three websites offered presentation mode, retrieval mode, productive recall, and productive recognition. Users will be familiarized with these words and their corresponding meanings via the flashcards and exercises on "form-meaning connections" and "written forms." Users can read the definitions, and then they can choose or type in the words. However, users cannot produce or choose the meanings of the target words on these three vocabulary flashcards and exercises. Nevertheless, these three vocabulary flashcard websites and exercises are not arranged in the order of increasing difficulty or learners' learning process or performance.

\subsection{Observations of Freshmen's Experience of Websites}

The instructor walked around the classroom and helped freshmen when they encountered difficulties in using these three websites. The three biggest problems these freshmen encountered included not able to log into the website (Example 1), unfamiliarity with the website (Example 2), and slow Internet service (Example 3).

In Example 1, a student complained about not being able to log into Study Stack via her Facebook account. Another student suggested that she should register for a new account. The teacher encouraged the student to register for a new account.

Example 1

S1: (Raises her hand)

T: What's your problem?

S1: I cannot log in the website with my Facebook account.

T: How about you close all browsers and try again?

S1: The same. I did, but I still could not log in with my Facebook account.

S2: Try to register a new account and you can $\log$ in.

T: Do it.

S1: Yes. 
In Example 2, a student forgot how to make online flashcards on Flashcard Exchange, despite the instructor having demonstrated how to do it in the previous class and at the beginning of that day's class. When the instructor explained and showed it to this student, he was able to recall the procedure for making online flashcards.

Example 2

S3: (Raises his hand)

T: Any problem?

S3: I don't know what I should do next.

T: First type in one word and choose one definition.

S3: You demonstrated how to do it in the beginning of the class. I remembered it. Thank you.

T: You're welcome.

In Example 3, a student complained that the Internet service was too slow in the computer laboratory, because everyone was online. She asked the teacher's permission to use her own iPad.

Example 3 Internet Service

S4: (Raises her hand)

T: What's wrong?

S4: It's too slow. Everyone is online. It takes forever to go to the next page. The computer in the laboratory is too slow. Can I use my own iPad?

T: Sure.

\subsection{Records of Students' Practice}

Participants completed all three exercises offered by Quizlet. As for the activities offered on Study Stack, the most completed activity was "Matching" (94\%), followed by "Crossword" (92\%), "Hangman" (91\%) and "Quiz" (91\%). Only 77\% participants completed the "Fill in the Blank" activity, which was not popular due to taking a longer time to complete. Therefore, the participants chose not to play this game. Fewer participants completed the two activities offered in Flashcard Exchange, "Memorize" (78\%) and "Test" (75\%) because some participants had difficulty logging into the website.

Poor Internet access is one of the problems that language teachers may face when incorporating technology into their vocabulary instruction (Mahmoudi, Samad, \& Razak, 2012; Park \& Son, 2009). Therefore, accessibility must be taken into consideration when teachers give online flashcard assignments. Students should be provided time to gain access to computers or the Internet so they can participate in computer-assisted language learning.

\subsection{Results of Interview}

Overall, participants affirmed that the online vocabulary websites helped them motivating them to learn English vocabulary, improving their vocabulary abilities, and increasing their vocabulary knowledge.

Example 4: I learned the spelling and word meanings of these words.

Example 5: I liked to review words on these websites because it was more fun and interesting to play online games than the traditional ways.

Example 6: I can learn and review words, spelling, and words meanings at my own pace.

Learners tend to hold positive learning attitudes toward using computers and multimedia in learning vocabulary, because they can have full autonomy and control the pace of learning (Ali et al., 2012). Browne and Culligan (2008, p. 13) claim that interactive vocabulary-learning games can induce automaticity:

The games are integrated with the spaced repetition system such that whether a learner reviews new target words with the flashcards or the games, whenever they correctly recognize the meaning of a word, it will be automatically forwarded to the next stage of the spaced repetition process.

Computers and games are interesting, because the use of computers creates an environment of enjoyment and fun while learners are acquiring a newly learned vocabulary and the interactive exercises allow processing of the new words at a deeper level (Ali et al., 2012; Browne \& Culligan, 2008). Therefore, integration of online vocabulary flashcard websites as individualized instruction can be a highly efficient method for learning vocabulary words. It is also beneficial since it can be done outside of class without utilizing precious classroom 
time (Tozcu \& Coady, 2004).

Of these three online vocabulary flashcard websites, participants liked Quizlet the most and Study Stack the least.

Example 7: I like Quizlet the most, because I used it last semester. I know how to use it. It's user friendly.

Example 8: I don't like Study Stack. First, it was difficult to log into. I tried to log in with my Facebook account but failed. Then I applied for a new account and tried to $\log$ in. But finally when I logged in, I did not know how to use it until my teacher and classmates helped me.

Example 9: I don't like Study Stack. There are too many exercises there. I had to play one game after another.

Of all the vocabulary activities offered on these three online vocabulary flashcard websites, participants liked Speller in Quizlet the most, followed by Test, Scatter, and Space Race in Quizlet. Chopped in Study Stack was the last favorite vocabulary activity.

Example 10: I like Spealler in Quizlet the most, because I read the definition and type in the corresponding word. This exercise helped me review spelling and meanings.

Example 11: I don't like Chopped in Study Stack. I have difficulties in putting parts of the word together.

Different features are integrated into interactive exercises and games depending on the purposes and objectives of vocabulary learning. If students are required to use target words in a sentence, fill-in-the-blanks will be an appropriate activity. A picture-matching exercise is suitable to assist students in remembering previously met words (Nation, 2005). In addition, learners can be asked to quickly match a word to the correct response, between the native language and target language, for example (Browne \& Culligan, 2008). Moreover, interactive drag-and-drop features enable learners to drag their answers and drop them into a blank space to complete a sentence structure (Ali et al., 2012).

\section{Discussion}

With regard to the first research question, "What word knowledge can the exercises on the online vocabulary flashcard websites provide?," the above data analysis indicates the word knowledge provided by the three online vocabulary flashcard websites is mainly Nation's (1994) form and words' meaning. While spelling is also included in Quizlet and Study Stack, pronunciation is emphasized in Quizlet. Of Nakata's (2011) 17 criteria, these online exercises and flashcards met eight of the criteria: flashcard creation, multilingual support, support for data entry, and flashcard set, presentation mode, retrieval mode, productive recall, and productive recognition.

Regarding the second research question, about Taiwanese college freshmen's attitudes toward and perceptions of these vocabulary flashcards, participants regarded these online vocabulary websites as helpful. The online flashcards helped them motivated them to learn English vocabulary, improve their vocabulary abilities, and increase their vocabulary knowledge, particularly in spelling. Of all the vocabulary activities offered on these three online vocabulary flashcard websites, participants liked Speller in Quizlet the most, followed by Test, Scatter, and Space Race in Quizlet.

In order to make online flashcards effective vocabulary-learning tools, suggestions are provided for the flashcard websites as in Figure 5.

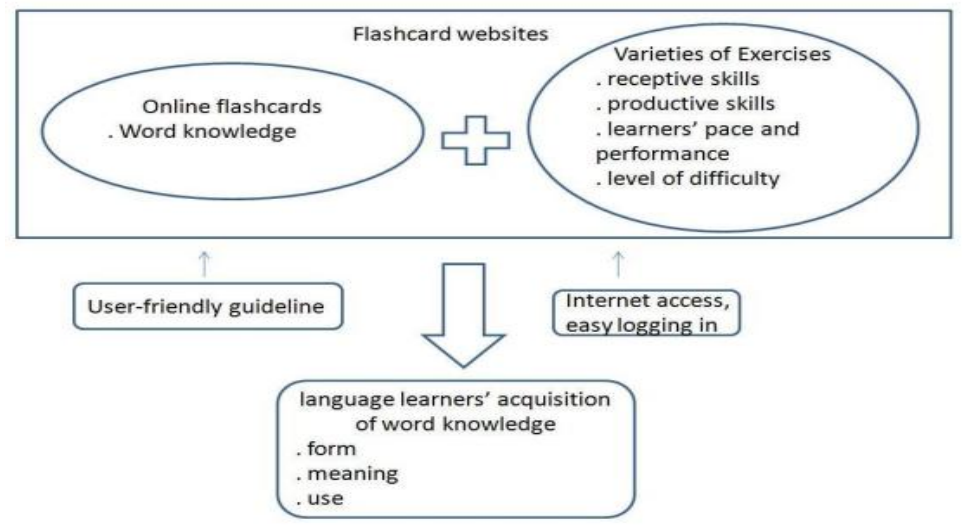

Figure 5. Effective flashcard websites on language learners' acquisition of word knowledge 
First, online vocabulary websites can provide user-friendly videos to facilitate users logging in, making flashcards, playing online games, etc. Internet access and easy logging in should be taken into consideration, too. Second, many words have different meanings and serve different functions in different sentences, texts, and even conversations (e.g., "give" in "give a hug" or "give a presentation" (Nagy \& Scott, 2000; Stahl, 2005). Moreover, learners should acquire word knowledge in terms of its form, use, and meaning. Therefore, online vocabulary flashcards should contain the following information: definitions in English, definitions in the learner's first language, parts of speech, sound files with native speaker pronunciation of the words, frequent collocations for each target word, and sample sentences (Browne \& Culligan, 2008). Moreover, online websites offer easy exercises for learners to practice and acquire both receptive and productive skills and the word knowledge in terms of form, meaning, and use.

\section{Conclusion}

This study aimed to compare and contrast college freshmen's perceptions of and attitudes toward three online vocabulary flashcard websites. Nakata (2011) uses 17 criteria to analyze and evaluate nine flashcard programs. This study moved beyond program and website evaluation. In addition to evaluating the flashcard data, this study used the results of classroom observations, learners' learning records, and interview to identify the features of the effective designs of flashcard website on language learners' acquisition of word knowledge. Moreover, goals, elements, and activities of Nation's (1994) “Activities for Vocabulary Learning" are used to compare and contrast three online vocabulary flashcard websites and exercises in terms of the word knowledge instruction and acquisition. The main results were the following two findings. First, these three online vocabulary flashcard websites mainly focused on Nation's (1994) form and words' meaning. These online exercises and flashcards met eight of Nakata's (2011) 17 criteria. Second, participants held positive attitudes toward learning and improving their vocabulary abilities via online flashcards and their related activities. Speller in Quizlet was the most popular activity chosen by participants, followed by Test, Scatter, and Space Race in Quizlet.

Based on the analysis of three online vocabulary flashcard websites and exercises and 64 Taiwanese college freshmen's word learning experience, this study presents a framework, as in Figure 5, for practitioners and language teacher editors on effective flashcard websites regarding language learners' acquisition of word knowledge. Online flashcards must include different word knowledge. Online word exercises should focus on developing learners' receptive and productive skills of word knowledge. Most importantly, these flashcard websites should provide user-friendly guidelines with easy Internet access and logging in. Therefore, language learners' word knowledge in form, meaning, and use can be acquired.

This study has two major limitations. First, the participants in this study were at intermediate proficiency level. The results of this study could only show intermediate-level learners' perceptions of and attitudes toward three online vocabulary flashcard websites. The results cannot be generalized to learners at different proficiency levels. Learners at different proficiency levels may have different perspectives on or preferences of different word activities offered by the online vocabulary flashcard websites. The second limitation of this study was the lack of grade reports on achievement tests, such as pre-test or post-test on vocabulary. The online flashcards and records of practicing and reviewing words on Quizlet, Study Stack, and Flashcard Exchange could only demonstrate participants' performance on online vocabulary flashcard websites, but could not statistically show improvement in participants' vocabulary learning.

Participants at different English proficiency levels can be recruited for further studies. These studies could compare and contrast the effects of online vocabulary flashcard websites on low, intermediate, and advanced proficiency-level EFL learners' vocabulary learning. Moreover, pre-tests or post-tests could be designed for future studies. Future studies could ask whether online vocabulary flashcard websites could make significant improvements to learners' vocabulary learning.

\section{References}

Ali, Z., Mukundan, J., Baki, R., Ayub, A. F. M. (2012). Second language learners' attitudes towards the methods of learning vocabulary. English Language Teaching, 5(4), 24-36. http://dx.doi.org/10.5539/elt.v5n4p24

Baleghizadeh, S., \& Ashoori, A. (2011). The impact of two instructional techniques on EFL learners' vocabulary knowledge: Flash cards versus word lists. MEXTESOL Journal, 35(2), 1-9. http://mextesol.net/journal/ index.php?page=journal\&id_article $=71$

Baturay, M., Yıldırım, S., \& Daloğlu, A. (2009). Effects of web-based spaced repetition on vocabulary retention of foreign language learners. Euraisan Journal of Educational Research, 34, 17-36. http://www.ejer.com.tr/ 0DOWNLOAD/pdfler/eng/1373500200.pdf 
Baumann, J. F., \& Kammeenui, E. J. (1991). Research on vocabulary instruction: Ode to Voltaire. In J. Flood, J. J. D. Lapp, \& J. R. Squire (Eds.), Handbook of research on teaching the English language arts (pp. 604-632). New York, NY: MacMillan.

Benjamin, A., \& Crow, J. T. (2010). Vocabulary at the center. Larchmont, NY: Eye on Education.

Browne, C., \& Culligan, B. (2008). Combining technology and IRT testing to build student knowledge of high frequency vocabulary. The JALT CALL Journal, 4(2), 3-16. http://journal.jaltcall.org/articles/4_2_ Browne.pdf

Daloğlu, A., Baturay, M., \& Yildirim, S. (2009). Designing a constructivitist vocabulary learning material. In R. C. V. Marriott, \& P. L. Torres (Eds.), Research on e-learning methodologies for language acquisition (pp. 186-203). New York: Information Science Reference.

Hu, H.-P., \& Deng, L.-J. (2007). Vocabulary acquisition in multimedia environment. US-China Foreign Language, 5(8), 55-59. http://citeseerx.ist.psu.edu/viewdoc/download?doi=10.1.1.116.5159\&rep=rep1\& type $=$ pdf

Hubbard, P. (2012). English teaching in the year 2030. TESOL Connection, May. http://newsmanager. commpartners.com/tesolc/issues/2012-05-01/3.html

Mahmoudi, E., Samad, A. A., \& Razak, N. Z. (2012). Attitude and students' performance in computer assisted English language learning for learning vocabulary. Procedia-Social and Behavioral Sciences, 66(7), 489-498. http://dx.doi.org/10.1016/j.sbspro.2012.11.293

Merriam, S. B. (2009). Qualitative research: A guide to design and implementation. Hoboken, NJ: Jossey-Bass.

Nakata, T. (2011). Computer-assisted second language vocabulary learning in a paired-associate paradigm: A critical investigation of flashcard software. Computer Assisted Language Learning, 24(1), 17-38. http://dx.doi.org/10.1080/09588331.2010.520675

Nagy, W. E., \& Scott, J. A. (2000). Vocabulary processes. In M. L. Kamil, P. Mosenthal, P. D. Pearson, \& R. Barr (Eds.), Handbook of reading research (pp. 269-284). Mahwah, NJ: Erlbaum.

Nation, I. S. P. (1994). New way in teaching vocabulary. Alexandria, VA: Teachers of English to Speakers of Other Languages.

Nation, I. S. P. (2001). Learning vocabulary in another language. Cambridge, UK: Cambridge University Press.

Nation, I. S. P. (2005). Teaching vocabulary. Asian EFL Journal, 3(7), 1-9. http://www.asian-efl-journal.com/ sept_05_pn.pdf

Park, C. N., \& Son, J. B. (2009). Implementing computer-assisted language learning in the EFL classroom: Teachers' perceptions and perspectives. International Journal of Pedagogies and Learning, 5(2). http://eprints.usq.edu.au/6887/1/Park_Son_IJPLv5n2_AV.pdf

Robinson, P. (2001). Cognition and second language instruction. Cambridge, UK: Cambridge University Press.

Stahl, S. A. (2005). Four problems with teaching word meanings (and what to do to make vocabulary an integral part of instruction). In E. H. Hiebert, \& M. L. Kamil (Eds.), Teaching and learning vocabulary: Bringing research to practice (pp. 95-114). Mahwah, NJ: Lawrence Erlbaum Associates.

Tozcu, A., \& Coady, J. (2004). Successful learning of frequent vocabulary through CALL also benefits reading comprehension and speed. Computer Assisted Language Learning, 17(5), 473-495. http://dx.doi.org/10.1080/0958822042000319674

Tuite, K., Pavlik, T., Fan, S. B., Robison, T., Jaffe, A., \& Liu, Y. E. (2012). Picard: A creative and social online flashcard learning game. In M. Consalvo, \& S. Feiner (Eds.), Proceedings of the International Conference on the Foundations of Digital Games (pp. 231-234). New York, NY: Association for Computing Machinery.

Yin, R. K. (2008). Case study research: Design and methods. Thousand Oaks, CA: Sage.

\section{Copyrights}

Copyright for this article is retained by the author(s), with first publication rights granted to the journal.

This is an open-access article distributed under the terms and conditions of the Creative Commons Attribution license (http://creativecommons.org/licenses/by/3.0/). 